\title{
A « wine bar » at the palliative care unit: A different way of caring
}

\author{
Virginie Guastella ${ }^{1 *}$, Aurélien Mulliez ${ }^{2}$, Andréa Tarot ${ }^{3}$ and Axelle Van Lander \\ ${ }^{1}$ Doctor, Palliative Care Unit PCU, CHU Clermont-Ferrand, France \\ ${ }^{2}$ Biostatistician, DRCI, CHU Clermont-Ferrand, France \\ ${ }^{3}$ Doctor, Palliative Care Unit, CHU Clermont-Ferrand, France \\ ${ }^{4}$ Psychologist, Palliative Care Unit, CHU Clermont-Ferrand, UPU ACCePPT, UCA, France
}

\begin{abstract}
Background: "Opening a Wine bar "at a Palliative Care Unit PCU is just a way to give the patients the opportunity of feeling alive.

Aim: This experience was carried out because in palliative medical practice the question of how to take care of patients and improve the quality of their remaining life expectancy is essential. Patients', carers' and relatives' opinions are good.

Design: We built an opinion survey with biostatisticians from the hospital (DRCI of the Universal Hospital UCH of Clermont-Ferrand) and it started in February 2015. We came up with three types of questionnaires to patients, relatives and caregivers for one year.

Setting/Participants: Patients were interviewed by professional staff who conducted face to face interviews. Relatives and caregivers were alone to answer.

Results: We got 115 answers, most of them are positive ones and give descriptive results. We also collected some verbatim answers. The results of this survey are gratifying. We are not so surprised because every day the patient's behaviour shows us how it can be important for them to be considered as still alive and not already dead without any desire.

Conclusion: It was important to perform this survey that demonstrates the humanistic dimension through a different way of caring. It confirms us in our first goal: allowing patients with serious diseases to enjoy some pleasure at the end of their life. This experience is going on and we are encouraged every day thanks to the patients' evidence or testimony.
\end{abstract}

\section{Introduction}

"Opening a Wine bar "at a Palliative Care Unit PCU is just a way to give the patients the opportunity of feeling alive. This project could be named "when the sociocultural habits re-humanize patients' care" [1]. The experience of "a wine bar "in a palliative care unit was carried out because in palliative medical practice the question of how to take care of patients and improve the quality of their remaining lives is essential. Human patients' dimension must be restored. It is also because palliative care tries to preserve the simple habits of life of patients that "happy eating and drinking "is at the centre of our concerns. Moreover, we have been helped by the nice survey performed by Catherine Legrand Sebille called "end of life, wine and food pleasures" [2-4]. Everybody is satisfied if not enthusiastic because it means that there is still a human dimension even in a hospital.

\section{Context}

In the summer of 2014, in accordance with the direction of the University Hospital of Clermont-Ferrand, we decided to put in place a Wine bar for the patients hospitalized in the PCU [5]. It is not possible to give patients who want to drink some wine anything except the bad "Villageoise "which is in a plastic bottle. All the members of the team have a deep respect for human beings and when someone who is seriously ill asks caregivers " shall I have a glass of wine ?" We feel really ashamed when we only have the hospital's wine to offer. Most patients we meet every day are terribly affected by their disease.
Some of them loose their hair, others are no longer able to do their personal grooming without the help of someone, others have lost many and many kilos with the feeling of being someone else. It is also difficult for the relatives.

For many of them it is probably the last sip of wine they taste so refusing or offering a bad one is considered as being disrespectful.

The aim of the project is to improve the patients' quality of life by demonstrating them that their life before illness is not completely over yet even if many modifications have happened in their body together with health degradation [6]. We first bought a wine cellar. We spoke about that in the press because we also organized a public conference to speak about pleasure at the end of life. Since the wine bar opened it has been the buzz for many months and thanks to that we now have serious notoriety which allows us sometimes to ask for some help. That allowed us to have plenty bottles of wine offered by vineyards from all over France.

${ }^{\star}$ Correspondence to: Virginie Guastella, PhD, Doctor, Palliative Care Unit PCU, CHU Clermont-Ferrand, France, E-mail: vguastella@chu-clermontferrand.fr

Key words: end of life, palliative care, quality of life, pleasure, wine, sensoriality, humanisation, meaning of care

Received: October 04, 2018; Accepted: November 02, 2018; Published: November 07, 2018 


\section{Methods}

\section{Design and setting}

This was an opinion survey. Together with biostatisticians from the hospital (DRCI of the Universal Hospital UCH of ClermontFerrand), we came up with three types of questionnaire to patients, to their relatives and also to caregivers for one year (questionnaires). They were built with several questions to appreciate and understand the feelings and the reactions of patients and relatives when they were informed that they were allowed to drink wine if they feel like it but also to observe what the caregivers thought. Questionnaires were submitted to patients and relatives after further discussion with the team. Patients who were asked to answer were not obviously a "consumers of wine". Patients were interviewed by professional staff who conducted face to face interviews. In the team, some professionals are referred especially to « the wine bar ». Relatives were alone to answer and caregivers too. We didn't want to influence them.

We could not be inspired by any other studies because opening a wine bar in a palliative care unit was a first in a University hospital.

\section{Population}

The inclusion criteria: patients and relatives over the age of 18 and able to speak and understand the questionnaires, without obvious cognitive and conscious impairment as judged by referring health professionals (RUDKIN score $=1$, NU Desc score $<2$ for patients); all the members of the palliative team were asked to participate in the study.

The non-inclusion criteria: refusal from the patient, sedated (RUDKIN score $>1$ ), unable to understand the purpose (Nu Desc score $\geq 2$ ), unable to communicate, when there had been the patient had addictive behaviours with alcohol with some bad effects on relationships.

We started the survey in February 2015. The wine bar had been opening since October 2014.

Patients were interviewed by professional staff who conducted face to face interviews.

The interviewers were identified clearly because they were caregivers who are referent of the project. Relatives were alone to answer and caregivers too.

Most of questions were wondered about perceptions and feelings. The answers were obviously very subjective. For most questions, we used a scale from 0 to 10 to appreciate the level : 0 means disagree and 10 totally agree. We decided, in an arbitrary way, to give a positive value to the answers $>7$.

Before using questionnaires, we decided to make a phase test and try them between us and with five colleagues who did not work in the PCU to be sure of their accessibility and to validate them. We also asked the psychologist of the team to give us her point of view.

Study population is described by frequencies and associated percentages for categorical data and by means of standard deviation for continuous data.

Statistics were computed with Stata software, version 12 (Stata Corp, College Station, TX, USA).

\section{Ethics, consent and permissions}

The study complies with the principles of the Declaration of Helsinki and French Good Clinical Practices. According to French laws (Article L1121-1, Law n²011-2012 29 December 2011 - art. 5), ethical approval was

not needed. All subjects participated on a voluntary basis. Consent for participation in the study was obtained from every participant.

\section{Results}

In total, we got 115 answers. It represents a participation of $84 \%$. All patients answered (Figures 1-4).

Thanks to these answers we are able to give descriptive results.

\section{Patients' opinion}

We obtained 44 answers from 19 men and 25 women, with an average age of 72 . For most of them they had some drinking wine habits during the main course or at a life's event.

Most patients are affected with carcinologic diseases (Table 1)

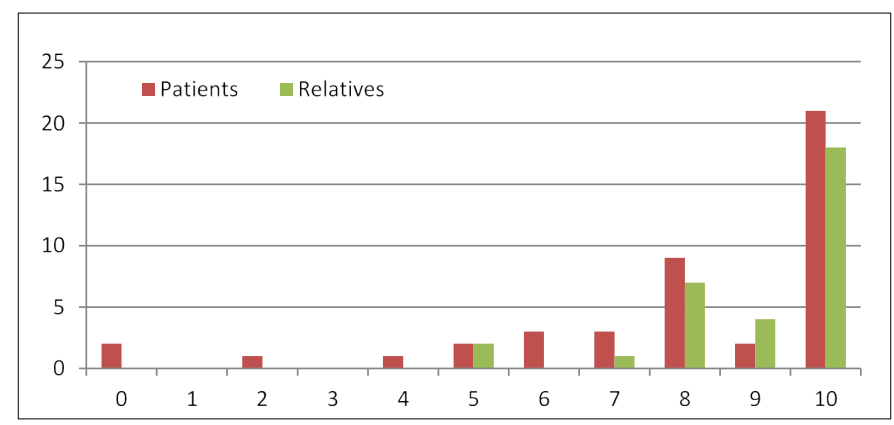

Figure 1. Setting up a « wine bar » in a PCU comes as a favourable action

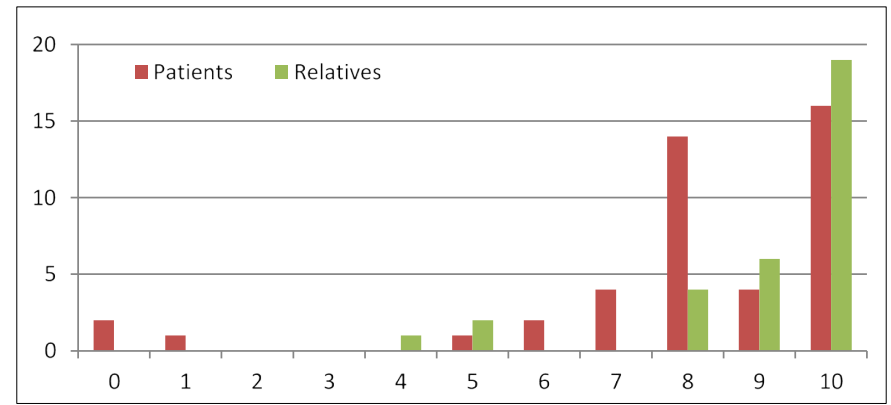

Figure 2. Wine fits in perfectly in pleasure meal

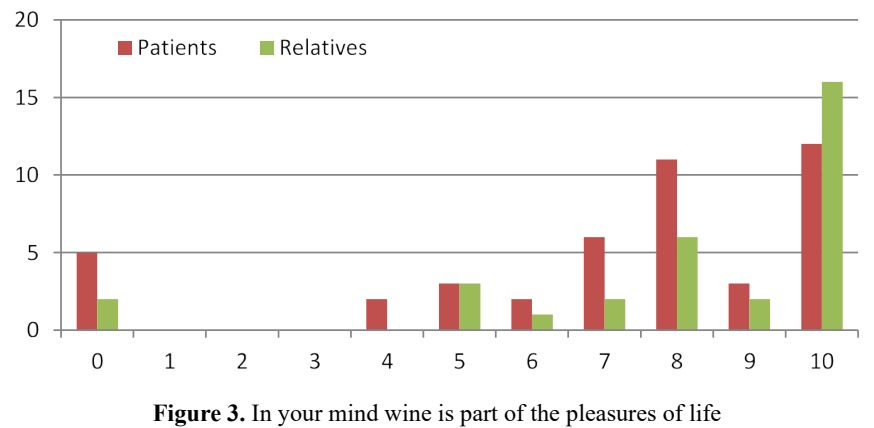

Figure 3. In your mind wine is part of the pleasures of life 


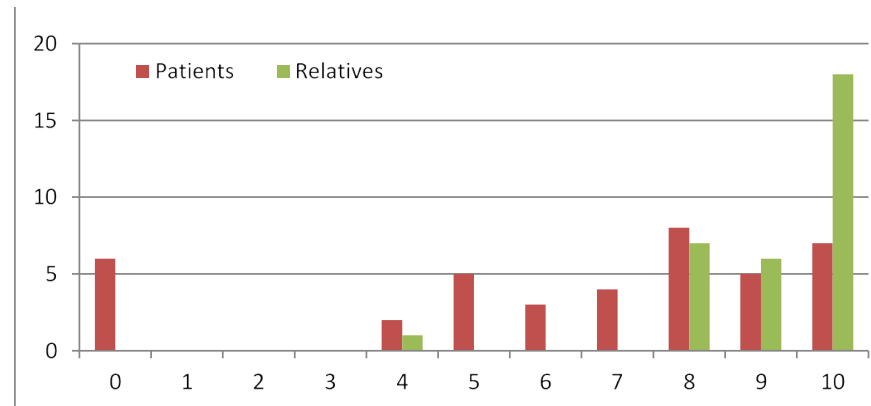

Figure 4. The proper place of wine shows the human dimension granted to care

Table 1. Different pathologies

\begin{tabular}{|c|c|}
\hline Total of patients & 44 \\
\hline Lung cancer & 18 \\
\hline Pancreatic cancer & 4 \\
\hline Colorectal cancer & 7 \\
\hline Prostatic cancer & 6 \\
\hline lymphoma & 2 \\
\hline Ovarian tumor & 2 \\
\hline Breast cancer & 2 \\
\hline Others & 3 \\
\hline
\end{tabular}

To the question: "Is setting up a wine bar in the Palliative Unit Care an appreciable action?" 36 out of $44(82 \%)$ patients gave an answer $>7$

"Has wine its proper place in every meal when it comes to pleasure and food" 38 out of 44 patients gave an answer $>7$

37 out of $44(84 \%)$ patients said that wine is one life's pleasure.

We asked patients if they had other pleasures such as reading, movies, sport, food, music or any others. Food comes first for 36 out of $41(88 \%)$ patients.

One of the questions in the survey was very often not easy to understand for patients. It asked if "wine's importance shows the human dimension dedicated to care". We got 24 out of 40 (60\%) people answering $>7$. But, we are not sure that they all understood what the question meant.

Some patients accepted to give their opinion and make some comments about the project.

The answers are written verbatim.

Positive ones:

The creation of a wine bar seems to be appropriate because it means that pleasures go on. The initiative is appreciated if it is validated by practitioners

It is a very nice idea because a patients' comfort can begin by having a glass of wine

Good with cheese

It is a good way to pass away feeling happy

It means they are taken care of

A patient said that he was afraid of his relatives' reaction because he was not allowed to have a drink when he was at home

A daily pleasure
Patients are allowed to go on with some of their habits

I totally agree with this idea especially when the wine is good

Disease should not prevent pleasure

Sharing a meal

It is our culture I come from a wine grower's family

It is a good way to communicate something else than disease

Good initiative

For the others but not for me

Negative ones:

I don't understand the necessity of

\section{Relatives' opinion}

We obtained 32 answers from relatives with an average age of 60.1 . The different kindships are in the Table 2. For most of them there are kindships ( 24 out of $32=75 \%$ ) and for $44 \%$ (14 out of 32 ), they were children.

To the question: "Is setting up a wine bar in the Palliative Unit Care an appreciable action?" The average score is 9 out of 10 on the scale with 30 out of 32 people ( $94 \%)$ answering $>7$.

"Opening a wine bar is meaningful". The average score is 9.4 out of 10 on the scale with 30 out of 31 (97\%) people answering $>7$.

"Has wine its proper place in every meal when it comes to pleasure and food" the average score 9 out of 10 on the scale with 29 out of 32 (90\%) people answering $>7$.

"Wine's importance shows the human dimension dedicated to care" the average score 9.1 out of 10 on the scale with 31 out of 32 (97\%) persons answering $>7$.

"Do you agree with the medical team when it tries to respect patients' habits through wine consumption" 29 out of 32 (90\%) gave a score $>7$.

"Are you in favour of offering a bottle of wine to your relative to make their meal better" the average score 8.4 out of 10 on the scale with 23 out of $30(77 \%)$ answering $>7$.

"Do you think that wine and specific therapy are compatible?" the average score 8.1 out of 10 on the scale with 23 out of $28(82 \%)$ answering $>7$. It was not an easy question and some people decided not to answer because they didn't know.

"Is Wine a life's pleasure for your relative?" the average score 8.1 out of 10 on the scale with 26 out of 32 (81\%) people answering $>7$.

"Is it important for you to favour the pleasures of tasting of your relative got?" for 29 out of $32(90 \%)$ drinks got a score $>7$ and an average score at 8.9; food got a score of 9.5.

Table 2. Relationship between patients and relatives

\begin{tabular}{|c|c|}
\hline Total of relatives & 32 \\
\hline Wife/Husband/partner & 9 \\
\hline Parents & 1 \\
\hline Children & 14 \\
\hline Friends & 3 \\
\hline Others & 5 \\
\hline
\end{tabular}


Relatives could also give their opinion and make some comments. We kept some sentences such as: "the setting up of a wine bar makes me feel better because it means that pleasures are not banned at the end of life" "it proves that quality must come before quantity".

\section{Caregivers' opinion}

We obtained 39 answers of caregivers with an average age of 37.6 . The different positions are in the Table 3.

To the question:" Is wine consumption a good manner to make care more human" 34 out of $39(87 \%)$ caregivers gave an answer $>7$. 36 out of $39(92 \%)$ caregivers said that this approach or this initiative is meaningful and that 32 out of 35 (91\%) patients are satisfied.

32 out of $36(89 \%)$ said that it could improve quality of life. We also tried to know if the caregivers thought that the Wine Bar improved the patients' quality of life. 36 out of 39 (92\%) with an average of 8 and 32 out of $36(88 \%)$ caregivers gave an answer $>7$.

One question was to know if the atmosphere in the unit had been changing since the Autumn of 2014 when the wine bar was set up. Its detailed family links, professional links and links between patients and caregivers. We didn't get the participation of all the caregivers.

About family links, 13 out of 24 (54\%) answered $>7$.

About professional links 11 out of 28 (39\%) answered $>7$.

About patients and caregivers, 8 out of 25 (32\%) answered $>7$.

These results are mentioned in the discussion part of this article.

The last part of the questionnaire for caregivers is open to everyone's ideas and opinions. They could tell whatever they thought (positive or negative) about the initiative. Here are some answers verbatim (but translated).

\section{Positive ones:}

The word "pleasure" often came up: "a way to offer pleasure even if the situations are complex", gustative pleasure, pleasure of memories, to give pleasure by embellishing daily life, the pleasure to give pleasure, the pleasure to taste a good wine,

It opens another free space for patients.

A new dynamic was born for the team, rehumanization of care, to share or to create a convivial space, to have some sensations or feelings emerge again.

Negative ones (translated quotations verbatim):

Looks like a luxury service,

New category of patients: those who are allowed to drink and others for whom it is forbidden,

Misunderstanding from some patients or relatives,

Table 3. positions of the different members of the team

\begin{tabular}{|c|c|}
\hline Total of positions & 38 \\
\hline Nurses & 9 \\
\hline Practionners & 7 \\
\hline Psychologists & 2 \\
\hline Caregivers & 6 \\
\hline Maids & 3 \\
\hline Voluntary workers & 11 \\
\hline
\end{tabular}

Bad impression felt when some relatives no longer show up with wine as a gift. It can be seen as a lack of care by some,

Pay attention as it can turn into a disagreement,

Misinterpretation of the name "wine bar",

Difference of viewpoints from inside and outside.

\section{Discussion}

This is the first study in which we tried to demonstrate that it is very important to consider that patients at the end of life are still alive with desire and pleasure such as drinking some good wine. ${ }^{7,89}$ The participation of $84 \%$ shows a good adhesion.

Even if wine consumption has declined in the last 50 years, it nevertheless stays the alcohol which is the most plebiscited by French people (56\% women and men) before hard alcohol such as whisky and vodka ..., beer and champagne (OMS).

About choosing the name of "wine bar "we have to clarify that there is no real counter in the unit.... It is only a wine cellar with 200 bottles. But it was interesting to collect some varying reactions. It allowed us to give some explanations. Moreover, it gave us the opportunity to speak in detail about Palliative Care and to answer these questions: What is it? Is it true that everybody is at the end of their life? So, are patients still able to appreciate anything? What is the real intention behind this initiative?

In the PCU we have 14 beds: $13+1$ "emergency" bed. Most of the time, we have 5 patients out of 14 (36\%) who drink wine. In 2015, we hospitalized 201 patients 105 male and 96 females, and we obtained 44 answers from patients. It quite well reflects what happens eventually. It also means that our aim is not that every patient drink but only answer patients' wishes.

The results of this survey are gratifying. We are not so surprised because every day the patient's behavior shows us how it can be important for them.

If we compare the answers, we can observe that patients and relatives all understand the human dimension of the project and feel reassured by this way of caring and are not afraid at all. The true meaning of the project is not discussed. Nonetheless, they sometimes need to have information that's why we meet them to explain our way of caring, our goal and the meaning behind it.

Nonetheless, it means that we have to look for money if we want to sustain those human successes and enhance quality of care. Even if the mediatization has not been appreciated by the whole team, it gives us a notoriety which is eventually not useless. We received some donations thanks to that and it can be interesting for other initiatives.

In the survey, participation of the caregivers is always difficult to get especially when the questions come from the hierarchy. They always think that it could be a way to judge them. Obviously, it was anonymous. It is very interesting to analyse the different commentaries

However, for patients and relatives it was not a problem to answer the questionnaires. They were most of the time glad to be requested because this way, they could show how this dimension of care was important to them. It was also an opportunity to speak about their life's pleasures. During this time, patients were speaking about sweet memories and diseases were out of their mind. It is a manner of distracting them. In hypnosis language we speak of regression as a good exercise to focus on something in order to forget about something else. 
Tasting wine is a sensory experience. It is a kind of hypnotic experience too. We can see that the second pleasure after wine is food.

It shows that even if for seriously sick people with anorexic symptoms, drinking and eating are still important. That is why we daily try to improve these two dimensions in care.

Because it is important to "reactivate the senses" and to distract from daily routine, we put in place several initiatives such as cooking workshops, painting exhibitions, games.

\section{Conclusion}

It was important to perform this survey that demonstrates the humanistic dimension through a different way of caring. In one year, it was difficult to obtain more answers, that is why the results are not powerful enough to go beyong description tell. Finally, the essence is that it confirms us in our first goal when we came up with this initiative of a "Wine bar: allowing patients with serious diseases to enjoy some pleasure at the end of their life. This experience is going on and we are encouraged every day thanks to the patients' evidence or testimony. The most important is to give meaning to everybody: meaning of the end of life for patients and relatives and meaning of caring for caregivers.
"Caregivers are able to take care of patients if their care carries some meaning".

\section{References}

1. Guastella V, Donnat C, Mesbauer M, Tinet A, Raynaud N, et al. (2015) When sociocultural habits re-humanize patient care: the experiment of a "wine bar" in a palliative care unit. 14th World Congress of the European Association for Palliative Care. European Journal of Palliative Care. Copenhague.

2. Tonin C (2013) Film Résultats de l'enquête de Catherine Legrand Seville: "Fins de vie. Plaisirs des vins et des nourritures".

3. Legrand Sebille C (2013) Préserver les plaisirs sensoriels en fin de vie. Les nourritures et le Vin.

4. Legrand Sebille C (2013) Fins de vie, éthique et société. Erès - 20124. CCNE. Rapport du CCNE sur le débat public concernant la fin de vie.

5. Durand J (2014) Vin de vie aux soins palliatifs de Clermont. Libération.

6. Guastella V, Raynaud N (2016) Le bar à vin ou une autre façon de prendre soin La revue de l'infirmière.

7. Canguilhem G (2002) Ecrits sur la médecine, Le Seuil, Le Champ freudien.

8. Courtois M, Thomas L-V (1991) Les Mots de la mort, Belin.

9. Le Breton D (1999) L'adieu au corps, Paris, éditions Métailié.

10. Poulain J-P (2013) Sociologies de l'alimentation, les mangeurs et l'espace social alimentaire, collection Quadrige PUF.

Copyright: $₫ 2018$ Guastella V. This is an open-access article distributed under the terms of the Creative Commons Attribution License, which permits unrestricted use, distribution, and reproduction in any medium, provided the original author and source are credited. 